\title{
Investigating Learner Preferences in the Application of Language Learning Strategies: A Comparison between Two Studies
}

\author{
Carmen M. Amerstorfer*
}

\begin{abstract}
The general topic of this article is language learning strategies, i.e. activities that foreign language learners purposefully choose to improve their skills in a foreign language and to reach desired learning outcomes. To highlight the importance of combining quantitative and qualitative information in a study about strategic language learning, the article uncovers some weaknesses that may be created by a one-sided perception. It hence looks exclusively at the quantitative data gained in a mixed-methods study (Amerstorfer 2016) that used a popular strategy inventory (SILL; Oxford 1990) to collect numerical information about the language learning strategies of five English as a foreign language (EFL) learners. The core of the article is a comparison of the quantitative data with three strategy categories that resulted from a previous study (Griffiths 2013). The article closes with the statement that a one-sided perception is not appropriate for a study about strategic foreign language learning.
\end{abstract}

Key words: Language learning strategies, quantitative data, qualitative data, mixed-methods research, strategy inventory for language learning, SILL, English as a foreign language, EFL

\footnotetext{
*Alpen-Adria-Universität Klagenfurt, Department of English; carmen.amerstorfer@aau.at
} 


\section{Introduction}

Language teachers, teacher educators, and researchers have inquired into language learning strategies for forty years. Numerous projects employing quantitative, qualitative, and mixed research methods have produced countless publications addressing terminological definitions, as well as theoretical aspects like taxonomies, and practical applications like strategy-based instruction. This paper is an extract of a doctoral dissertation that studies language learning strategies in the context of cooperative learning. It will demonstrate the self-perception of strategic behaviour of five foreign language learners during cooperative English lessons. The article is based on a case study conducted at an Austrian secondary school. It aims to assess the similarities and differences of each participant's strategy use in comparison with three strategy types identified as significant for certain achievement levels (Griffiths 2003, 2013). The comparison will reveal ambiguous results. It will further highlight the importance of clearly defined terminology and of carefully selected research tools and methods.

First, past research into language learning strategies will be briefly summarised. Second, the research design, environment, and methodology will be described with reference to the purpose of this article. Third, the data collected will be analysed and compared, which will finally lead to some reflections highlighting the importance of acknowledging individual learner differences.

\section{Research into language learning strategies}

Ever since Rubin's first mention of language learning strategies (LLSs) in 1975, the topic has been of immense interest to scholars around the globe. In the past forty years heated discussions about appropriate terminology, categorisation schemes, and practical applications of LLSs have occupied the academic community (for example, Hosenfeld 1976; Naiman et al. 1978; O’Malley et al. 1985; Wenden 1987; O’Malley and Chamot 1990; Oxford 1990, 1999, 2011; Weinstein et al. 2000; Griffiths 2008, 2013; Cohen 2012). Consensus has been met regarding the general notion of LLSs by describing them as actions undertaken by learners to support learning processes and/or to produce language output.

A milestone in the development of LLS research is Oxford's (1990) categorisation system in which she divides LLSs into direct strategies (memory, cognitive, and compensation strategies) and indirect strategies (metacognitive, affective, and social strategies). The general distinction between direct and indirect strategies was first drawn by Rubin $(1975,1981)$ and later expanded by Oxford. Figuratively speaking, Rubin created the skeleton and Oxford put flesh on the bones. Oxford's comprehensive classification demonstrates what each of the six sub-categories encompasses and provides a total of 62 examples. Based on this categorisation scheme, Oxford developed the Strategy 
Inventory for Language Learning (SILL), which is one of the most commonly used instruments in the field of LLS research to date. The SILL consists of fifty statements about LLS usage that are rated by participants on a 5-point scale from 1, never/almost never true of me, to 5 , always/almost always true of me (see table 1). The statement ratings enable the calculation of participants' average overall LLS use as well as an average application of strategies belonging to the six strategy types $(\mathrm{A}=$ memory, $\mathrm{B}=$ cognitive, $\mathrm{C}=$ compensation, $\mathrm{D}=$ metacognitive, $\mathrm{E}=$ affective, and $\mathrm{F}=$ social strategies). The overall aim of the SILL is to identify and quantify LLSs based on learners' selfperception.

Oxford nominated high, medium, and low frequency of strategy use as follows:

\begin{tabular}{l|l|l}
\multirow{2}{*}{ High } & Always or almost always used & 4.5 to 5.0 \\
\cline { 2 - 3 } & Usually used & 3.5 to 4.4 \\
\hline Medium & Sometimes used & 2.5 to 3.4 \\
\hline \multirow{2}{*}{ Low } & Generally not used & 1.5 to 2.4 \\
\cline { 2 - 3 } & Never or almost never used & 1.0 to 1.4
\end{tabular}

Table 1: Key to determine high, medium, and low frequency of LLS use by Oxford (1990)

The SILL profiles below quantitatively demonstrate how the participants of the study described in this paper ranked different strategy types (parts A-F) in sum and on average. Oxford's key corresponds with average ratings for each strategy type. An overall sum of all ratings and an average rating of all 50 statements are given at the bottom of each participants' SILL profile.

In her PhD thesis, Griffiths (2003) used the SILL to investigate whether there is a relationship between highly frequently used LLSs and successful language learning. Griffiths developed SILL profiles of 348 participants aged 14 to 64 from 21 different nations. The group under investigation consisted of approximately one-third male and two-thirds female participants with proficiency levels ranging from elementary to advanced (Griffiths 2013). Griffiths focused on strategies most frequently used by elementary learners and by advanced learners, as well as on strategies applied highly frequently across all proficiency levels. In comparison to the elementary language learners, the advanced participants reported an overall higher frequency in LLS application. Additionally, the study revealed that advanced learners reported using nine times as many different LLSs than elementary learners. Based on these findings, Griffiths identified three groups of LLSs (see table 2), namely base, core, and plus strategies. 


\begin{tabular}{|c|c|c|c|}
\hline & Sub-group & Item & Statement (paraphrased for brevity ${ }^{1}$ ) \\
\hline \multirow{9}{*}{ 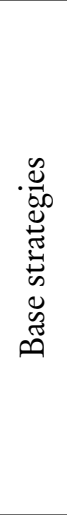 } & Memory & 3 & I create images of new words \\
\hline & Memory & 6 & I use flashcards to remember new words \\
\hline & Memory & 7 & I physically act out new words \\
\hline & Memory & 8 & I review English lessons often \\
\hline & Memory & 9 & I use location to remember new words \\
\hline & Compensation & 26 & I make up words if I don't know the right ones \\
\hline & Metacognitive & 34 & I plan my schedule to have time to study \\
\hline & Affective & 43 & I write my feelings in a diary \\
\hline & Affective & 44 & I talk to someone else about how I feel \\
\hline \multirow{12}{*}{ 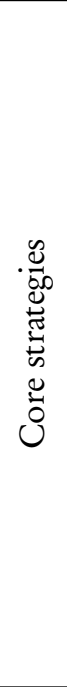 } & Cognitive & 11 & I try to talk like native speakers \\
\hline & Cognitive & 12 & I practise the sounds of English \\
\hline & Cognitive & 15 & I watch TV or movies in English \\
\hline & Compensation & 25 & When I can't think of a word I use gestures \\
\hline & Compensation & 29 & If I can't think of a word I use a synonym \\
\hline & Metacognitive & 30 & I try to find many ways to use English \\
\hline & Metacognitive & 31 & I use my mistakes to help me do better \\
\hline & Metacognitive & 32 & I pay attention to someone speaking in English \\
\hline & Metacognitive & 33 & I try to find how to be a better learner \\
\hline & Metacognitive & 38 & I think about my progress in learning English \\
\hline & Social & 45 & I ask others to speak slowly or repeat \\
\hline & Social & 49 & I ask questions in English \\
\hline \multirow{15}{*}{ 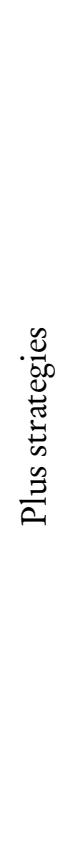 } & Memory & 1 & I think of relationships \\
\hline & Cognitive & 10 & I say or write new words several times \\
\hline & Cognitive & 14 & I start conversations in English \\
\hline & Cognitive & 18 & I skim read then read carefully \\
\hline & Cognitive & 19 & I look for similar words in my own language \\
\hline & Cognitive & 20 & I try to find patterns in English \\
\hline & Cognitive & 21 & I divide words into parts I understand \\
\hline & Cognitive & 22 & I try not to translate word for word \\
\hline & Compensation & 24 & I guess the meaning of unfamiliar words \\
\hline & Compensation & 27 & I read without looking up every new word \\
\hline & Affective & 39 & I try to relax when afraid of using English \\
\hline & Affective & 40 & I encourage myself to speak even when afraid \\
\hline & Social & 46 & I ask for correction when I talk \\
\hline & Social & 48 & I ask for help from English speakers \\
\hline & Social & 50 & I try to learn the culture of English speakers \\
\hline
\end{tabular}

Table 2: Base, core, and plus strategies (adapted from Griffiths 2013, 59-64) 
According to Griffiths, base strategies are used highly frequently by elementary learners, while proficient learners prefer strategies from the plus category. Core strategies are applied highly frequently by learners across all proficiency levels.

This article presents the quantitative results of a recent case study (Amerstorfer 2016) in comparison with Griffiths' (2013) findings about base, core, and plus strategies. Specifically, it focuses on base and plus strategies because core strategies, according to Griffiths, are used by learners of all proficiency levels. Before the comparison will be made, the research design, environment and methodology of the case study will be explained.

\section{Research design, environment, and methodology}

The case study at hand investigates five learners' strategic behaviour during cooperative EFL lessons. All participants are female and between 14 and 18 years of age. To protect anonymity, pseudonyms are used. The participants' shared first language (L1) is German. In this paper, a clear distinction is drawn between proficiency levels and achievement levels. Proficiency levels are regularly assessed in school and defined by the $\mathrm{CEFR}^{2}$. The participants' achievement levels, on the other hand, reflect the grades they received in the subject English in the semester reports (table 3). The high-level achievers in this study received A-grades, while the low-level achievers received D-grades. In other words, the achievement level describes how well the pupils performed in English in the first semester of the academic year 2013/14.

\begin{tabular}{lcc}
\hline Participant's name & Overall proficiency in EFL & Achievement level \\
\hline \hline Christina & A2 & low \\
Lisa & A2+ & high \\
Paula & B1/B1+ & high \\
Stella & B2 & high \\
Sabrina & B2 & low \\
\hline
\end{tabular}

Table 3: Participants' proficiency and achievement levels

The research environment of the study is CoOperative Open Learning (COOL), a statefunded teaching concept that was introduced in 1996 in Austri (Cooltrainers, n.d.). The teaching philosophy underlying COOL is the Dalton Plan ${ }^{3}$ (Parkhurst 1922), a humanistic teaching approach developed in the early 1920s. In COOL schools, pupils take increased responsibility for their learning processes and outcomes. About a third to half

\footnotetext{
1 For the original SILL statements, see Oxford 1990, 292-299

2 Common European Framework of Reference for Languages (Council of Europe 2014)

3 The original title is "Dalton Laboratory Plan," but the shortened version is commonly used in the literature.
} 
of a COOL timetable consists of open learning periods (COOL lessons) in which pupils work independently of a teacher. The remainder are regular lessons that are teachercentred, similar to those in mainstream schools in Austria. The class teachers involved in COOL meet regularly to discuss any current business and to design assignments and tasks for COOL lessons. During those lessons, pupils are encouraged to work collaboratively, support each other, and offer feedback on each other's work. They self-regulate their learning and take responsibility for the learning progress. Pupils in COOL schools are aware that what they cannot finish in school must be completed in their leisure time.

The starting point of this paper is the five participants' self-perception regarding their use of language learning strategies, which will be demonstrated in their SILL profiles (tables 4, 6, 8, 10, and 12). Second, the strategies that were rated highest and lowest will be isolated to enable a comparison with Griffiths' (2013) findings (tables 5, 7, 9, 11, and 13). The purpose of this paper is, therefore, to analyse how each participant's self-perception of LLS use compares to Griffiths' categories.

\section{Analysis of data}

For a comparison with Griffiths' (2013) study, this section will summarise and analyse the quantitative results of each participant. Only the highest and lowest SILL ratings are taken into account.

\subsection{Christina (low-level achiever)}

\begin{tabular}{llccc} 
& & & \multicolumn{2}{c}{ Participant's rating } \\
Part & Strategy type & Number of items & Sum & Average \\
\hline \hline A. & Memory strategies & 9 & 29 & 3.22 \\
B. & Cognitive strategies & 14 & 49 & 3.50 \\
C. & Compensation strategies & 6 & 19 & 3.17 \\
D. & Metacognitive strategies & 9 & 39 & 4.33 \\
E. & Affective strategies & 6 & 17 & 2.83 \\
F. & Social strategies & 6 & 19 & 3.17 \\
\hline & & 50 & 172 & 3.44 \\
\hline
\end{tabular}

Table 4: Christina’s SILL profile

According to Oxford's (1990) interpretation of the SILL, Christina uses language learning strategies at a medium to high frequency (3.44). She uses metacognitive strategies most frequently (4.33) and affective strategies least frequently (2.83). She favours cognitive (3.50) over memory (3.22) strategies followed by compensation and social strategies (both 3.17). 


\begin{tabular}{|c|c|c|c|c|}
\hline SILL & Item & $\mathrm{BCP}$ & Lowest rating $(1=$ Never or almost never true of me $)$ & comparison \\
\hline A. & 3 & B & $\begin{array}{l}\text { I connect the sound of a new English word and an image or picture of the } \\
\text { word to help me remember the word. }\end{array}$ & disagreement \\
\hline E. & 43 & B & I write my feelings in a language learning diary. & disagreement \\
\hline SILL & Item & $\mathrm{BCP}$ & Highest rating $(5=$ Always or almost always true of me $)$ & comparison \\
\hline A. & 8 & B & I review English lessons often. & agreement \\
\hline B. & 10 & $\mathrm{P}$ & I say or write new English words several times. & disagreement \\
\hline C. & 25 & $\mathrm{C}$ & When I can't think of a word during a conversation in English, I use gestures. & (core) \\
\hline D. & 32 & $\mathrm{C}$ & I pay attention when someone is speaking English. & (core) \\
\hline D. & 34 & B & I plan my schedule so I will have enough time to study English. & agreement \\
\hline D. & 35 & & I look for people I can talk to in English. & $\mathrm{n} / \mathrm{a}^{4}$ \\
\hline D. & 38 & $\mathrm{C}$ & I think about my progress in learning English. & (core) \\
\hline E. & 40 & $\mathrm{P}$ & $\begin{array}{l}\text { I encourage myself to speak English even when I am afraid of making a } \\
\text { mistake. }\end{array}$ & disagreement \\
\hline
\end{tabular}

Table 5: Christina's lowest- and highest-rated SILL statements ${ }^{5}$ in comparison with Griffiths (2013)

In contrast to Griffiths' view that base strategies are typically used by low-level achievers, the two strategies rated lowest by Christina (items 3 and 43) both belong to the category of base strategies. However, Christina's highest ratings for two other base strategies (items 8 and 34) are in line with Griffiths' results. Christina further rated three core strategies highest (items 25,32 , and 38). Core strategies were found to be used by all pupils, so they are not relevant in this comparison. Christina's high rating for two plus strategies (items 10 and 40) deviates from Griffiths' findings because those are believed to be usually representative of high-level achievers. One strategy (item 35) rated highest by Christina is not mentioned in any of the categories. With two strong agreements (items 8 and 34) and four strong disagreements (items 3, 10, 40, and 43) Christina's strategy use does not represent that of Griffiths' typical low-level achiever.

\footnotetext{
${ }^{4} \mathrm{n} / \mathrm{a}=$ not applicable because not included in Griffiths' study

5 SILL = strategy type according to Oxford (1990); BCP = base, core, plus strategies according to Griffiths (2013)
} 


\subsection{Sabrina (low-level achiever)}

\begin{tabular}{llccc} 
& & & \multicolumn{2}{c}{ Participant's rating } \\
Part & Strategy type & Number of items & Sum & Average \\
\hline \hline A. & Memory strategies & 9 & 20 & 2.22 \\
B. & Cognitive strategies & 14 & 37 & 2.64 \\
C. & Compensation strategies & 6 & 17 & 2.83 \\
D. & Metacognitive strategies & 9 & 27 & 3.00 \\
E. & Affective strategies & 6 & 18 & 3.00 \\
F. & Social strategies & 6 & 16 & 2.67 \\
\hline & & 50 & 135 & 2.70 \\
\hline
\end{tabular}

Table 6: Sabrina's SILL profile

Sabrina's SILL profile shows that her overall strategy use is mediocre (2.7). She prefers metacognitive and affective strategies (both 3) and uses memory strategies least frequently (2.222). According to Griffiths' study, low-level achievers favour memory strategies, but Sabrina is the opposite.

Sabrina's lowest-rated strategies consist in equal numbers of base strategies, which Griffiths found typical of low-level achievers (items 6, 7, 26, and 43), plus strategies, which are typical of high-level achievers (items 14, 18, 20, and 48), and strategies that were not mentioned in Griffiths' scheme (items 5, 16, 35, and 49). No core strategies were rated lowest by Sabrina, but all six highest-rated strategies are core strategies, which are used by learners across all levels. A remarkably large number of high ratings, as in Sabrina's case, cannot be satisfyingly compared to Griffiths' study because core strategies were not found representative of either achievement group. The analysis of Sabrina's quantitative data does, therefore, not show any particularly significant similarity with Griffiths' results. The opposite is the case for the four statements rated lowest by Sabrina that were described as characteristic of low-level achievers. All in all, Sabrina's strategy use is not representative of a typical low-level achiever. 


\begin{tabular}{lllll}
\hline SILL & Item & BCP & Lowest rating (1 = Never or almost never true of me) & comparison \\
\hline \hline A. & 5 & & I use rhymes to remember new English words. & $\mathrm{n} / \mathrm{a}$ \\
A. & 6 & B & I use flashcards to remember new English words. & disagreement \\
A. & 7 & B & I physically act out new English words. & disagreement \\
B. & 14 & P & I start conversations in English. & $\mathrm{n} / \mathrm{a}$ \\
B. & 16 & & I read for pleasure in English. & $\mathrm{n} / \mathrm{a}$ \\
B. & 18 & P & I first skim an English passage (read over the passage quickly) then go back & $\mathrm{n} / \mathrm{a}$ \\
& & & and read carefully. & $\mathrm{n} / \mathrm{a}$ \\
B. & 20 & P & I try to find patterns in English. & disagreement \\
C. & 26 & B & I make up new words if I do not know the right ones in English. & $\mathrm{n} / \mathrm{a}$ \\
D. & 35 & & I look for people I can talk to in English. & disagreement \\
E. & 43 & B & I write down my feelings in a language learning diary. & $\mathrm{n} / \mathrm{a}$ \\
F. & 48 & P & I ask for help from English speakers. & $\mathrm{n} / \mathrm{a}$ \\
F. & 49 & & I ask questions in English. & \\
& & & & comparison \\
\hline SILL & Item & BCP & Highest rating (5 = Always or almost always true of me) & (core) \\
\hline \hline B. & 11 & C & I try to talk like native English speakers. & (core) \\
B. & 12 & C & I practice the sounds of English. & (core) \\
C. & 25 & C & When I can't think of a word during a conversation in English, I use gestures. \\
D. & 32 & C & I pay attention when someone is speaking English. & (core) \\
D. & 33 & C & I try to find out how to be a better learner of English. & (core) \\
F. & 45 & C & If I do not understand something in English, I ask the other person to slow & (core) \\
& & & down or say it again. &
\end{tabular}

Table 7: Sabrina's lowest- and highest-rated SILL statements in comparison with Griffiths (2013)

\subsection{Paula (high-level achiever)}

\begin{tabular}{llccc} 
& & & \multicolumn{2}{c}{ Participant's rating } \\
Part & Strategy type & Number of items & Sum & Average \\
\hline \hline A. & Memory strategies & 9 & 17 & 1.89 \\
B. & Cognitive strategies & 14 & 43 & 3.07 \\
C. & Compensation strategies & 6 & 19 & 3.17 \\
D. & Metacognitive strategies & 9 & 25 & 2.78 \\
E. & Affective strategies & 6 & 15 & 2.50 \\
F. & Social strategies & 6 & 20 & 3.33 \\
\hline & & 50 & 139 & 2.78 \\
\hline
\end{tabular}

Table 8: Paula’s SILL profile 


\begin{tabular}{|c|c|c|c|c|}
\hline SILL & Item & $\mathrm{BCP}$ & Lowest rating $(1=$ Never or almost never true of $\mathrm{me})$ & comparison \\
\hline A. & 3 & B & $\begin{array}{l}\text { I connect the sound of a new English word and an image or picture of the } \\
\text { word to help me remember the word. }\end{array}$ & $\mathrm{n} / \mathrm{a}$ \\
\hline A. & 4 & & $\begin{array}{l}\text { I remember a new English word by making a mental picture of a situation } \\
\text { in which the word might be used. }\end{array}$ & $\mathrm{n} / \mathrm{a}$ \\
\hline A. & 5 & & I use rhymes to remember new English words. & $\mathrm{n} / \mathrm{a}$ \\
\hline A. & 6 & B & I use flashcards to remember new English words. & $\mathrm{n} / \mathrm{a}$ \\
\hline A. & 7 & B & I physically act out new English words. & $\mathrm{n} / \mathrm{a}$ \\
\hline B. & 12 & $\mathrm{C}$ & I practice the sounds of English. & (core) \\
\hline B. & 21 & $\mathrm{P}$ & $\begin{array}{l}\text { I find the meaning of an English word by dividing it into parts that I under- } \\
\text { stand. }\end{array}$ & disagreement \\
\hline C. & 26 & B & I make up new words if I do not know the right ones in English. & $\mathrm{n} / \mathrm{a}$ \\
\hline E. & 43 & B & I write down my feelings in a language learning diary. & $\mathrm{n} / \mathrm{a}$ \\
\hline E. & 44 & B & I talk to someone else about how I feel when I am learning English. & $\mathrm{n} / \mathrm{a}$ \\
\hline SILL & Item & BCP & Highest rating $(5=$ Always or almost always true of me $)$ & comparison \\
\hline A. & 9 & B & $\begin{array}{l}\text { I remember new English words or phrases by remembering their location } \\
\text { on the page, on the board, or on a street sign. }\end{array}$ & disagreement \\
\hline B. & 10 & $\mathrm{P}$ & I say or write new English words several times. & agreement \\
\hline B. & 18 & $\mathrm{P}$ & $\begin{array}{l}\text { I first skim an English passage (read over the passage quickly) then go back } \\
\text { and read carefully. }\end{array}$ & agreement \\
\hline
\end{tabular}

Table 9: Paula's lowest- and highest-rated SILL statements in comparison with Griffiths (2013)

Paula's SILL profile reveals that her overall language learning strategy use (2.78) is below the average frequency level defined by Oxford (1990). She favours social (3.33), compensation (3.17), and cognitive (3.07) strategies over metacognitive (2.78) and affective (2.50) strategies. According to her SILL profile, she hardly ever applies memory strategies (1.89).

Out of the ten strategies Paula rated lowest, six (items 3, 6, 7, 26, 43, and 44) are base strategies. Following Griffiths' theory, it appears that Paula has a tendency to avoid strategies that are typically used by low-level achievers. However, Griffiths study focuses on strategies with high ratings without considering low-rated strategies, which makes a comparison difficult. Other strategies that Paula never or almost never applies are items 12 (core), 21 (plus), 4, and 5 (not mentioned by Griffiths). Out of the total of fifty items, Paula gave the highest rating to only three: item 9, a base strategy typical of low-level achievers, and items 10 and 18, which both belong to the plus category. 


\subsection{Stella (high-level achiever)}

\begin{tabular}{llccc} 
& & & \multicolumn{2}{c}{ Participant's rating } \\
Part & Strategy type & Number of items & Sum & Average \\
\hline \hline A. & Memory strategies & 9 & 28 & 3.11 \\
B. & Cognitive strategies & 14 & 53 & 3.79 \\
C. & Compensation strategies & 6 & 24 & 4.00 \\
D. & Metacognitive strategies & 9 & 29 & 3.22 \\
E. & Affective strategies & 6 & 18 & 3.00 \\
F. & Social strategies & 6 & 19 & 3.17 \\
\hline & & 50 & 171 & 3.42 \\
\hline
\end{tabular}

Table 10: Stella's SILL profile

Stella's frequency of strategy use is 3.42 on average. Her most used strategy types are compensation strategies (4.00) closely followed by cognitive (3.79), metacognitive (3.22), social (3.17), memory (3.11), and affective (3.00) strategies. There is little divergence between her most and least frequently used strategy types on average.

\begin{tabular}{lllll}
\hline SILL & Item & BCP & Lowest rating $(1=$ Never or almost never true of me $)$ & comparison \\
\hline \hline A. & 6 & B & I use flashcards to remember new English words. & $\mathrm{n} / \mathrm{a}$ \\
E. & 43 & B & I write down my feelings in a language learning diary. & $\mathrm{n} / \mathrm{a}$
\end{tabular}

\begin{tabular}{|c|c|c|c|}
\hline SILL & Item & $\mathrm{BCP}$ & Highest rating $(5=$ Always or almost always true of me $)$ \\
\hline A. & 1 & $\mathrm{P}$ & $\begin{array}{l}\text { I think of relationships between what I already know and new things I learn } \\
\text { in English. }\end{array}$ \\
\hline A. & 9 & B & $\begin{array}{l}\text { I remember new English words or phrases by remembering their location } \\
\text { on the page, on the board, or on a street sign. }\end{array}$ \\
\hline B. & 10 & $\mathrm{P}$ & I say or write new English words several times. \\
\hline B. & 19 & $\mathrm{P}$ & $\begin{array}{l}\text { I look for words in my own language that are similar to new words in En- } \\
\text { glish. }\end{array}$ \\
\hline B. & 22 & $\mathrm{P}$ & I try not to translate word-for-word. \\
\hline C. & 27 & $\mathrm{P}$ & I read English without looking up every new word. \\
\hline C. & 29 & $\mathrm{C}$ & $\begin{array}{l}\text { If I can't think of an English word, I use a word or phrase that means the } \\
\text { same thing. }\end{array}$ \\
\hline E. & 39 & $\mathrm{P}$ & I try to relax whenever I feel afraid of using English. \\
\hline E. & 40 & $\mathrm{P}$ & $\begin{array}{l}\text { I encourage myself to speak English even when I am afraid of making a } \\
\text { mistake. }\end{array}$ \\
\hline
\end{tabular}

comparison

agreement

disagreement

agreement

agreement

agreement agreement (core)

agreement agreement

Table 11: Stella's lowest- and highest-rated SILL statements in comparison with Griffiths (2013) 
Out of the five participants, Stella shows the most similarity to Griffiths' results. She ranked two strategies (items 6 and 43) lowest which both belong to the base category and are typically used frequently by low-level achievers. Seven of the nine strategies with the highest ranking are plus strategies (items 1, 10, 19, 22, 27, 39, and 40), which is indicative of high-level achievers in Griffiths' study. The two remaining strategies ranked highest belong to the base category (item 9) and to the core category (item 29). All of the strategies ranked highest or lowest by Stella were mentioned in Griffiths' study. Accordingly, Stella represents the results of a typical high-level achiever.

\subsection{Lisa (high-level achiever)}

\begin{tabular}{llccc} 
& & & \multicolumn{2}{c}{ Participant's rating } \\
Part & Strategy type & Number of items & Sum & Average \\
\hline \hline A. & Memory strategies & 9 & 17 & 1.89 \\
B. & Cognitive strategies & 14 & 45 & 3.21 \\
C. & Compensation strategies & 6 & 18 & 3.00 \\
D. & Metacognitive strategies & 9 & 25 & 2.78 \\
E. & Affective strategies & 6 & 10 & 1.67 \\
F. & Social strategies & 6 & 16 & 2.67 \\
\hline & & 50 & 131 & 2.62 \\
\hline
\end{tabular}

Table 12: Lisa's SILL profile

Lisa's preferred strategy types are cognitive strategies (3.21) closely followed by compensation strategies (3.00). She sometimes applies metacognitive (2.78) and social (2.67) strategies but rarely memory (1.89) and affective (1.67) strategies. Her overall use of language learning strategies, according to Oxford's (1990) SILL analysis, is mediocre.

Lisa gave the lowest possible rating to 14 items. Five of them (items 6, 7, 26, 43, and 44) are base strategies. Six of the strategies ranked lowest by Lisa (items 4, 5, 16, 17, 28, and 41) are not mentioned in Griffiths' study. The remaining three items Lisa declared as never or almost never true of her (items 39,46 , and 48 ) belong to the group of plus strategies which are typically used by high-level achievers. Therefore, Lisa's results do not mirror the results of a typical high-level achiever in Griffiths' study. Regarding the highest ratings, Lisa declared six statements to be always or almost always true of her. One of them (item 23) does not belong to any of the three categories as defined by Griffiths. Two (items 29 and 45) are core strategies, and three (items 14, 21, and 22) are plus strategies. 


\begin{tabular}{|c|c|c|c|c|}
\hline SILL & Item & $\mathrm{BCP}$ & Lowest rating $(1=$ Never or almost never true of me $)$ & comparison \\
\hline A. & 4 & & $\begin{array}{l}\text { I remember a new English word by making a mental picture of a situation } \\
\text { in which the word might be used. }\end{array}$ & $\mathrm{n} / \mathrm{a}$ \\
\hline A. & 5 & & I use rhymes to remember new English words. & $\mathrm{n} / \mathrm{a}$ \\
\hline A. & 6 & B & I use flashcards to remember new English words. & $\mathrm{n} / \mathrm{a}$ \\
\hline A. & 7 & B & I physically act out new English words. & $\mathrm{n} / \mathrm{a}$ \\
\hline B. & 16 & & I read for pleasure in English. & $\mathrm{n} / \mathrm{a}$ \\
\hline B. & 17 & & I write notes, messages, letters, or reports in English. & $\mathrm{n} / \mathrm{a}$ \\
\hline C. & 26 & B & I make up new words if I do not know the right ones in English. & $\mathrm{n} / \mathrm{a}$ \\
\hline C. & 28 & & I try to guess what the other person will say next in English. & $\mathrm{n} / \mathrm{a}$ \\
\hline E. & 39 & $\mathrm{P}$ & I try to relax whenever I feel afraid of using English. & disagreement \\
\hline E. & 41 & & I give myself a reward or treat when I do well in English. & $\mathrm{n} / \mathrm{a}$ \\
\hline E. & 43 & B & I write down my feelings in a language learning diary. & $\mathrm{n} / \mathrm{a}$ \\
\hline E. & 44 & B & I talk to someone else about how I feel when I am learning English. & $\mathrm{n} / \mathrm{a}$ \\
\hline F. & 46 & $\mathrm{P}$ & I ask English speakers to correct me when I talk. & disagreement \\
\hline F. & 48 & $\mathrm{P}$ & I ask for help from English speakers. & disagreement \\
\hline SILL & Item & $\mathrm{BCP}$ & Highest rating ( $5=$ Always or almost always true of me) & comparison \\
\hline B. & 14 & $\mathrm{P}$ & I start conversations in English. & agreement \\
\hline B. & 21 & $\mathrm{P}$ & $\begin{array}{l}\text { I find the meaning of an English word by dividing it into parts that I under- } \\
\text { stand. }\end{array}$ & agreement \\
\hline B. & 22 & $\mathrm{P}$ & I try not to translate word-for-word. & agreement \\
\hline B. & 23 & & I make summaries of information that I hear or read in English. & $\mathrm{n} / \mathrm{a}$ \\
\hline C. & 29 & $\mathrm{C}$ & $\begin{array}{l}\text { If I can't think of an English word, I use a word or phrase that means the } \\
\text { same thing. }\end{array}$ & (core) \\
\hline F. & 45 & $\mathrm{C}$ & $\begin{array}{l}\text { If I do not understand something in English, I ask the other person to slow } \\
\text { down or say it again. }\end{array}$ & (core) \\
\hline
\end{tabular}

Table 13: Lisa's lowest- and highest-rated SILL statements in comparison with Griffiths (2013) 


\section{Reflections}

As summarised in table 14, the five participants' SILL responses partly support Griffiths' findings about base, core, and plus strategies. While Paula's and Lisa's strong agreements equal the occurrences of strong disagreements, Christina's and Sabrina's results show more disagreement than agreement. Stella appears to reflect Griffiths' (2013) findings best with a much higher number of strong agreements than disagreements.

\begin{tabular}{lcc}
\hline $\begin{array}{l}\text { Participant's name } \\
\text { (achievement level) }\end{array}$ & $\begin{array}{c}\text { Number of SILL items } \\
\text { with strong agreement }\end{array}$ & $\begin{array}{c}\text { Number of SILL items } \\
\text { with strong disagreement }\end{array}$ \\
\hline \hline Christina (low) & 2 & 4 \\
Sabrina (low) & 0 & 4 \\
Paula (high) & 2 & 2 \\
Stella (high) & 7 & 1 \\
Lisa (high) & 3 & 3 \\
\hline
\end{tabular}

Table 14: Numerical agreements and disagreements with the strategy types defined by Griffiths (2013)

An analysis of the results reveals a few problems. First of all, the originally designed SILL (Oxford 1990) is outdated. Some strategies that are often used by pupils in schools today are not included in the original version of the SILL, particularly those related to modern technologies. Second, participants' responses to the SILL are purely based on self-perception and memory. Research tools that solely depend on a person's own judgement and recollection lack reliability and may not reflect reality. Third, the SILL provides only quantitative results. While this may be unproblematic in a large-scale study, it is inappropriate for a case study with a small sample size. The three issues raised call for an inclusion of other research methods.

Through semi-structured initial interviews and recorded lesson observations combined with stimulated recall interviews, the shortcomings mentioned above can be overcome (see Amerstorfer 2017 for more information). Strategies that are not included in the SILL can be added, and numerical results supplemented with qualitative information. The purpose of this article, however, is to compare the quantitative findings generated through the SILL with Griffiths' categorisation of base, core, and plus strategies. Therefore, all qualitative aspects have been neglected. As was mentioned in the introduction, this article is a snapshot of a larger study. The additional research methods mentioned in this paragraph are, in fact, applied in the study (Amerstorfer 2016) but not reported here.

The data analysis notably reveals that Griffiths' study exhibits some weaknesses. First, there is a terminological issue that needs clarification. On the one hand, Griffiths inquires about the relationship among successful language learning and certain language learning strategies and strategy types. On the other hand, learner proficiency levels are mentioned in the analysis of the results. As was explained above, proficiency levels 
should clearly be distinguished from achievement levels. To clarify, while two learners can be on the same proficiency level (for instance, B1 according to the CEFR), one can perform well in the school subject English and receive an A-grade in the semester report, while the other one can be a low-level achiever and get a $\mathrm{D}$-grade because overall they did not do so well in that particular semester. Such terminological ambiguities can lead to misinterpretations of results. Second, only highly frequently used strategies are analysed in Griffiths' study. Strategies with low ratings are disregarded. This raises a number of questions, for instance, what can low-rated SILL statements say about a learner's language learning strategy use? Are certain strategies avoided by learners? If yes, why? Third, according to Griffiths, core strategies are used by learners across all levels, which again poses questions about the meaning of low or high ratings for the corresponding SILL statements in the core category. In a SILL-only approach, a comparison between high-level and low-level achievers' application of core strategies becomes irrelevant. However, adding a qualitative component can reveal interesting results, such as reasons for certain strategy choices or connections between single strategies (Amerstorfer 2016). Fourth, how should SILL statements that are not included in any of Griffiths' categories be handled? In order to draw a valid comparison, they would have to be excluded from the study. That would, however, cause additional complications because high or low ratings for them also convey meaning.

All of these factors lead to a high degree of ambiguity in the comparison between Griffiths' study and the SILL results extracted from the case study reported in this article. As was mentioned before, the study mixes a number of research methods in order to prevent flaws resulting from a SILL-only approach. A combination of SILL outcomes with qualitative information leads to comprehensive findings that acknowledge individual learner differences in the application of language learning strategies. Nevertheless, the purpose of this article was a comparison between the participants' SILL results and Griffiths' categories (2013).

\section{References}

Amerstorfer, Carmen M. 2016. "Situated Strategy Use in Cooperative Learning: A Descriptive Case Study of Five Learners of English as a Foreign Language.” Unpublished PhD thesis, AlpenAdria-Universität Klagenfurt.

Amerstorfer, Carmen M. 2017. "Mixing Methods: Investigating Self-regulated Strategies in a Cooperative EFL Learning Environment.” In Language Learning Strategies and Individual Learner Characteristics: Situating Strategy Use in Diverse Contexts, edited by Rebecca L. Oxford and Carmen M. Amerstorfer. London: Bloomsbury.

Boekaerts, Monique, Paul R. Pintrich, and Moshe Zeidner, eds. 2000. Handbook on Self-Regulation. San Diego, CA: Academic Press. 
Cohen, Andrew D. 2007. "Coming to Terms with Language Learning Strategies: Surveying the Experts.” In Language Learner Strategies: Thirty Years of Research and Practice, edited by Andrew D. Cohen and Ernesto Macaro. 29-45. Oxford: Oxford University Press.

Cohen, Andrew D., and Ernesto Macaro, eds. 2007. Language Learner Strategies: Thirty Years of Research and Practice. Oxford: Oxford University Press.

Cohen, Andrew D. 2012. "Strategies: The Interface of Styles, Strategies, and Motivation on Tasks.” In Psychology for Language Learning: Insights from Research, Theory and Practice, edited by Sarah Mercer, Stephen Ryan, and Marion Williams. 136-50. Houndmills: Palgrave Macmillan.

Cooltrainers. n.d. “COOL Cooperatives Offenes Lernen.” Accessed September 29, 2015. http:// www.cooltrainers.at.

Council of Europe. 2014. "Common European Framework of Reference for Languages: Learning, Teaching, Assessment (CEFR).” Accessed September 29, 2015. http://www.coe.int/t/dg4/ linguistic/cadre1_en.asp.

Griffiths, Carol. 2003. "Language Learning Strategy Use and Proficiency: The Relationship between Patterns of Reported Language Learning Strategy (LLS) Use by Speakers of Other Language (SOL) and Proficiency with Implications for the Teaching/Learning Situation.” PhD thesis, University of Auckland. Accessed September 09, 2013. http://hdl.handle.net/2292/9.

Griffiths, Carol. 2008. Lessons from Good Language Learners. Cambridge: Cambridge University Press.

Griffiths, Carol. 2013. The Strategy Factor in Successful Language Learning. Second Language Acquisition 67. Bristol: Multilingual Matters.

Hosenfeld, Carol. 1976. “Learning about Learning: Discovering our Students' Strategies.” Foreign Language Annals 9 (2): 117-29.

Mercer, Sarah, Stephen Ryan, and Marion Williams, eds. 2012. Psychology for Language Learning: Insights from Research, Theory and Practice. Houndmills: Palgrave Macmillan.

Naiman, Neil, Maria Fröhlich, H. H. Stern, and Angie Todesco. 1978. The Good Language Learner. Toronto: Ontario Institute for Studies in Education. Research in Education Series No. 7.

O’Malley, J. Michael, Anna U. Chamot, Gloria Stewner-Manzanares, Lisa Küpper, and Rocco P. Russo. 1985. "Learning Strategies Used by Beginning and Intermediate ESL Students." Language Learning 35 (1): 21-46.

O’Malley, J. Michael and Anna U. Chamot. 1990. Learning Strategies in Second Language Acquisition. Cambridge: Cambridge University Press.

Oxford, Rebecca L. 1990. Language Learning Strategies: What Every Teacher Should Know. Boston: Heinle \& Heinle.

Oxford, Rebecca 1999. "Learning Strategies." In Concise Encyclopedia of Educational Linguistics, edited by Bernhard Spolsky and R. E. Asher, 518-22. Amsterdam: Elsevier.

Oxford, Rebecca L. and Karen Schramm. 2007. "Bridging the Gap between Psychological and Sociocultural Perspectives on L2 Learner Strategies." In Language Learner Strategies: Thirty Years of Research and Practice, edited by edited by Andrew D. Cohen and Ernesto Macaro, 47-68. Oxford: Oxford University Press.

Oxford, Rebecca L. 2011. Teaching and Researching Language Learning Strategies. Harlow: Pearson/Longman. 
Oxford, Rebecca L., and Carmen M. Amerstorfer, eds. 2017. Language Learning Strategies and Individual Learner Characteristics: Situating Strategy Use in Diverse Contexts. London: Bloomsbury.

Parkhurst, Helen. 1922. Education on the Dalton Plan. New York: E.P. Dutton \& Company.

Rubin, Joan. 1975. “What the 'Good Language Learner' Can Teach Us.” TESOL Quarterly 9 (1): 41-51.

Rubin, Joan. 1981. "The Study of Cognitive Processes in Second Language Learning." Applied Linguistics 11 (2): 117-31.

Spolsky, Bernhard, and R. E. Asher, eds. 1999.Concise Encyclopedia of Educational Linguistics. Amsterdam: Elsevier.

Weinstein, Claire E., Jenefer Husman, and Doug R. Dierking. 2000. "Self-Regulation Interventions with a Focus on Learning Strategies." In Handbook on Self-Regulation, edited by Monique Boekaerts, Paul R. Pintrich, and Moshe Zeidner, 727-47. San Diego, CA: Academic Press.

Wenden, Anita. 1987. “Conceptual Background and Utility.” In Learner Strategies in Language Learning, edited by edited by Anita Wenden and Joan Rubin, 3-13. Englewood Cliffs, NJ: Prentice-Hall.

Wenden, Anita, and Joan Rubin, eds. 1987. Learner Strategies in Language Learning. Englewood Cliffs: Prentice-Hall. 